\title{
Dependence on Membrane Lipids of the Effect of Vanadate on Calcium and ATP Binding to Sarcoplasmic Reticulum ATPase
}

\author{
Pankaj Medda and Wilhelm Hasselbach \\ Max-Planck-Institut für Medizinische Forschung, Abteilung Physiologie, Jahnstr. 29, \\ D-6900 Heidelberg, Bundesrepublik Deutschland
}

Z. Naturforsch. 39 c, 1137-1140 (1984); received August 31, 1984

\begin{abstract}
Sarcoplasmic Reticulum ATPase, Vanadate, Calcium, Adenosinetriphosphate
The affinity of the sarcoplasmic reticulum transport ATPase for calcium and ATP is not affected by lipid depriviation while vanadate binding is completely abolished. Lipid substitution restores vanadate binding as well as the vanadate induced disappearance of the enzyme's high affinity calcium and nucleotide binding sites. Nucleotide binding is simultaneously restored with the displacement of vanadate from the enzyme following the occupation of its low affinity calcium binding sites.
\end{abstract}

\section{Introduction}

As previously reported, the calcium transport enzyme of the sarcoplasmic reticulum membranes becomes enzymatically inactive on lipid deprivation which, however, does not affect the binding of the enzyme's most important ligands calcium and magnesium ATP [1]. The lipids are evidently not essential for the binding of these ligands but for their processing in the reaction chain which is characterized by transitions between high and low affinity calcium binding states in conjunction with changes in the enzyme's state of phosphorylation [2]. In this work, we report on results concerning the lipid requirement of the mutual interaction of four ligands with the calcium transport enzyme. This kind of interaction has been realized to play an essential role in the transformation of chemical into osmotic energy. In the experiments reported here, we made use of the recent findings that the enzyme's low affinity calcium binding state can more easily be stabilized by vanadate than by its natural ligand phosphate $[3,4]$. We show that calcium, ATP and ADP are displaced from the native enzyme by vanadate, while it does not affect ligand binding to the delipidated enzyme. It is demonstrated that the mutual interaction of the ligands is restored after lipid supplementation.

\section{Materials and Methods}

Sarcoplasmic reticulum vesicles were isolated from rabbit skeletal muscle as described by Hassel-

Reprint requests to Prof. Dr. Wilhelm Hasselbach.

0341-0382/84/1100-1137\$01.30/0 bach and Makinose [5]. Lipid depletion of the sarcoplasmic membranes was performed by digestion with phospholipase $\mathrm{A}_{2}$ followed by a treatment with bovine serum albumin [6]. Reconstitution of the lipid deprived calcium transport enzyme, calcium, ATP and ADP binding were performed as described in Ref. [6-8]. Vanadate binding was determined with $\left[{ }^{48} \mathrm{~V}\right]$ vanadate. Protein bound $\left[{ }^{48} \mathrm{~V}\right]$ vanadate was determined by Millipore filtration technique and measuring the radio-activity remaining on the filters. In some cases vanadate binding was measured indirectly as previously described [3].

\section{Results}

As recently shown, vanadate abolishes high affinity calcium binding to native sarcoplasmic reticulum membranes [3]. In contrast, however, vanadate does not affect calcium binding to lipid deprived preparations (Tables I and II). Addition of oleic acid to lipid deprived preparations at a lipid/ protein ratio of 0.3 which completely reactivates the enzyme [6], also restores the calcium displacing effect of vanadate. $0.5 \mathrm{~mm}$ vanadate reduces calcium binding from $5.1 \mathrm{nmol} / \mathrm{mg}$ to $2.8 \mathrm{nmol} / \mathrm{mg}$ at a free calcium concentration of $4 \mu \mathrm{M}$. The data given in Table I further show that at a calcium concentration of $0.1 \mathrm{~mm}$, calcium is not reduced but enhanced. This applies to native as well as to reconstituted preparations [9]. For the reverse reaction, the displacement of vanadate by calcium, it has been demonstrated for native membranes that calcium must initially interact with low affinity calcium binding sites facing the lumen of the 
vesicular preparation [3, 9]. These internal low affinity sites are rapidly accessible only after the membranes have been made calcium permeable with the ionophore A 23187. Relipidation of the lipid deprived preparations also restitutes the displacement of bound vanadate by calcium (Fig. 1). The reaction exhibits the same concentration dependence as observed for native calcium permeable vesicles indicating that reconstitution results in preparations having freely accessible low affinity calcium binding sites.

Table I. Calcium binding to native, lipid deprived and reconstituted sarcoplasmic reticulum vesicles in the absence and in the presence of $0.5 \mathrm{~mm}$ vanadate. The standard assay contained $40 \mathrm{~mm} \mathrm{KCl}, 20 \mathrm{~mm}$ imidazole $\mathrm{pH} 7,5 \mathrm{mM} \mathrm{MgCl}_{2}$ and $0.2 \mathrm{mg}$ protein $/ \mathrm{ml}$. The free calcium concentrations were adjusted with EGTA. The preparations were incubated for $20 \mathrm{~min}$ in the respective solutions at room temperature $\left(20-22^{\circ} \mathrm{C}\right)$. The data are given as $\underline{\bar{X}} \pm \operatorname{SEM}(n=3-5)$.

\begin{tabular}{llr}
\hline Enzyme preparations & \multicolumn{2}{l}{$\begin{array}{l}\text { Free calcium } \\
\text { concentration }[\mu \mathrm{M}]\end{array}$} \\
& 4 & \multicolumn{2}{c}{100} \\
\cline { 2 - 3 } & \multicolumn{3}{l}{$\begin{array}{l}\text { Calcium binding } \\
\text { nmol/mg protein }\end{array}$} \\
\hline Native vesicles & $6.8 \pm 0.3$ & $9.8 \pm 0.4$ \\
Native vesicles + vanadate & $2.3 \pm 0.1$ & $10.9 \pm 0.5$ \\
Lipid deprived vesicles & $5.0 \pm 0.3$ & $9.2 \pm 0.5$ \\
Lipid deprived vesicles + vanadate & $4.7 \pm 0.3$ & $9.0 \pm 0.5$ \\
Lipid deprived vesicles + oleic acid & $5.1 \pm 0.3$ & $9.4 \pm 0.5$ \\
(1:0.3) & & \\
Lipid deprived vesicles + oleic acid & $2.8 \pm 0.1$ & $13.0 \pm 0.6$ \\
(1:0.3) + vanadate & & \\
\hline
\end{tabular}

ATP or ADP binding, like calcium binding, does not require membrane lipids $[7,10]$. In parallel to calcium, ATP bound to native preparations is displaced by vanadate (Fig. 2). Conversely, when vanadate is displaced by calcium, nucleotide binding is simultaneously reestablished (Fig. 3). As shown for calcium, delipidation makes nucleotide binding vanadate insensitive and lipid supplementation restores the displacing effect of vanadate for the nucleotide. The reverse reaction, the displacement of bound vanadate by ATP, was only observed when millimolar concentrations of ATP were applied [3].

\section{Discussion}

In native sarcoplasmic reticulum membrane vesicles vanadate displaces not only calcium but also ATP from externally located high affinity binding sites. The results presented here, further show that neither the displacement of calcium nor of ATP is mediated by lipid deprived preparations, although these preparations have retained their binding capacity for the enzyme's most important substrates calcium and magnesium-ATP. Evidently, the binding of these ligands and the necessary structural rearrangement of the enzyme within the binding regions can take place independently of the enzyme's lipid surrounding. In contrast to calcium and ATP, inorganic phosphate does not measurably react with the delipidated preparations. Like inorganic phosphate, vanadate is not bound by the lipid deprived preparations.

Table II. The effect of vanadate on calcium, ATP and ADP binding to different vesicle preparations at room temperature. Calcium binding at $4 \mu \mathrm{M}$ free calcium and $\mathrm{pH} 7$ in presence of 0.1 vanadate measured by Millipore filtration technique [7, 8]. ATP and ADP binding at $10 \mu \mathrm{M}$ nucleotide concentration in presence of $0.1 \mathrm{~mm}$ vanadate were measured as described under "Materials and Methods". Bound vanadate at $10 \mu \mathrm{m}$ was determined with $\left[{ }^{48} \mathrm{~V}\right]$ vanadate by Millipore filtration technique.

\begin{tabular}{lllll}
\hline Enzyme preparation & $\begin{array}{l}\text { Calcium- } \\
\text { enzyme } \\
\text { complex }\end{array}$ & $\begin{array}{l}\text { ATP-enzyme } \\
\text { complex }\end{array}$ & $\begin{array}{l}\text { ADP-enzyme } \\
\text { complex }\end{array}$ & $\begin{array}{l}\text { Vanadate- } \\
\text { enzyme } \\
\text { complex }\end{array}$ \\
\cline { 2 - 5 } & nmol/mg protein & & \\
\hline Native vesicles & 6.8 & 3.0 & 1.1 & 4.0 \\
Native vesicles + vanadate & 2.3 & 0.0 & 0.0 & 0.2 \\
Lipid deprived vesicles & 5.0 & 2.0 & 0.8 & \\
Lipid deprived vesicles + vanadate & 4.7 & 1.9 & 0.8 & 2.1 \\
Lipid deprived vesicles + oleic & 5.1 & 1.8 & 0.0 & \\
acid (1:0.3) & 2.8 & 0.0 & & \\
Lipid deprived vesicles + oleic & & & & \\
acid (1:0.3) + vanadate & &
\end{tabular}




\section{$\overline{\bar{i}}$}

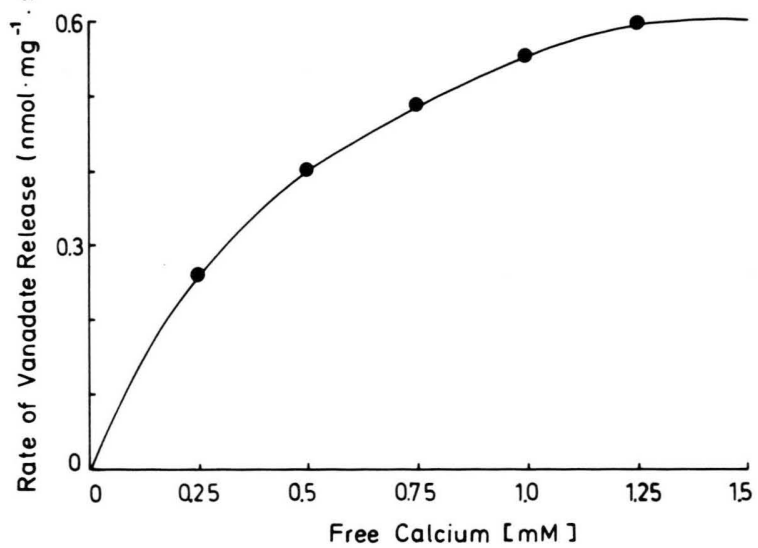

Fig. 1. Dependence on calcium of the rate of vanadate release from oleate-reconstituted vesicles. Vanadate binding at $0.1 \mathrm{~mm}$ was performed as described previously [3]. Calcium was added to give the free concentrations indicated on the abscissa. The rate of vanadate release was calculated from the amount of vanadate free enzyme formed during $5 \mathrm{~s}$ after calcium addition. The vanadate free enzyme was monitored by ATP supported phosphoprotein formation [3].

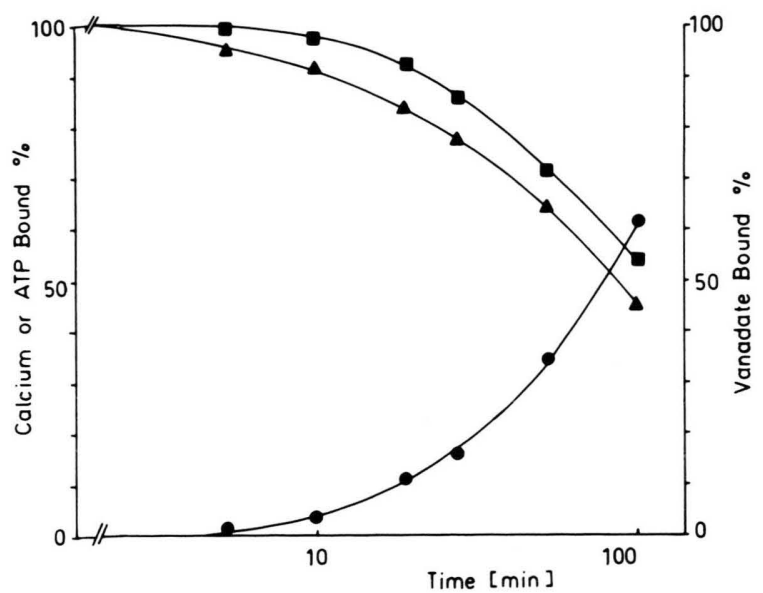

Fig. 2. Increase of vanadate binding to native sarcoplasmic reticulum vesicles and the decline of calcium and ATP binding. Vanadate binding was determined by phosphorylation of the vanadate free enzyme as described before [3]. $10 \mu \mathrm{M}$ ATP and $10 \mu \mathrm{M}$ calcium were added to the $0.1 \mathrm{~mm}$ vanadate containing assay at the time given on the abscissa. Binding was terminated by Millipore filtration. The experiments were performed at $0^{\circ} \mathrm{C}$. ( $\mathbf{( a )}$ bound ATP, ( $\mathbf{\Delta})$ bound calcium, ( $)$ bound vanadate. $100 \%$ on the ordinate represents $3 \mathrm{nmol} \mathrm{ATP} / \mathrm{mg}, 7.5 \mathrm{nmol} \mathrm{Ca} / \mathrm{mg}$ and $7 \mathrm{nmol} \mathrm{V} / \mathrm{mg}$. Maximal vanadate binding was measured with $\left[{ }^{48} \mathrm{~V}\right]$ vanadate by Millipore filtration.

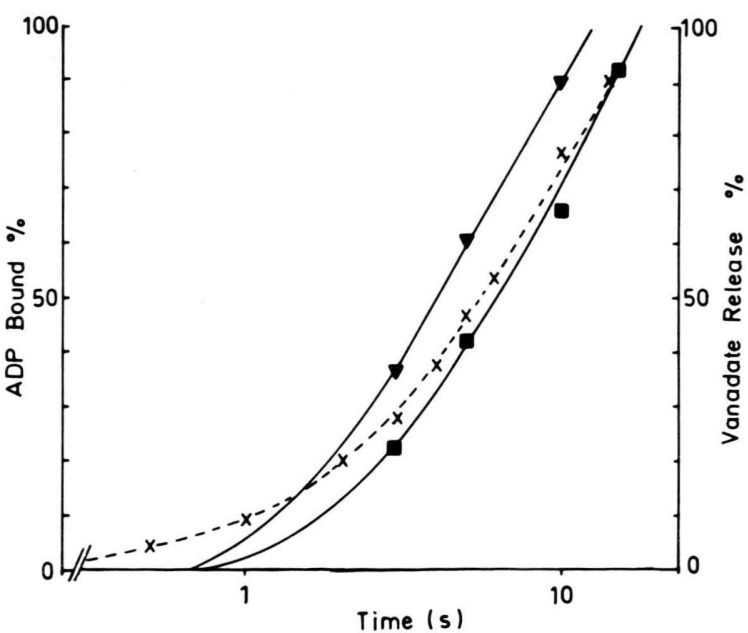

Fig. 3. Time course of the calcium induced release of vanadate from calcium permeable native and reconstituted vesicles, followed by ADP binding and ATP supported phosphoprotein formation of the vanadate free enzyme. The protein was incubated at room temperature with $0.5 \mathrm{~mm}$ vanadate for $5 \mathrm{~min}$ in the presence of $1 \mathrm{~mm}$ EGTA as previously described [3]. Vanadate release was induced by the addition of $1.5 \mathrm{mM} \mathrm{CaCl}$. At the times given on the abscissa, ADP binding was initiated by the addition of $10 \mu \mathrm{M}\left[{ }^{14} \mathrm{C}\right] \mathrm{ADP}$ and immediately terminated by Millipore filtration [8]. Native vesicles in the presence of $10 \mu \mathrm{M}$ A 23187 ( $(\mathbf{a})$, delipidated vesicles + oleic acid ( $\mathbf{v})$. Vanadate release $(x)$ from native vesicles monitored by phosphoprotein formation as previously described [3]. For $100 \%$ ADP binding compare Table II.

Consequently, vanadate can displace neither calcium nor the adenine nucleotides from their binding sites. It is shown that relipidation by oleic acid largely restores vanadate binding and thus restores its ability to displace calcium and ATP from their high affinity binding sites. Relipidation not only restores the calcium displacing effect of vanadate, but also the reverse reaction, the displacement of vanadate by calcium. When vanadate is displaced by calcium, in parallel to the release of vanadate from the enzyme, its nucleotide binding is restored. As shown for calcium, also ATP has to be applied at high concentrations in order to displace vanadate from the enzyme [3]. Evidently, in the vanadate bound state, the enzyme only exhibits low affinity for calcium and ATP.

A most interesting observation confirmed in this study, is the significant increase in the total number of calcium binding sites of native as well as of relipidated preparations at calcium concentration $\sim 0.1 \mathrm{~mm}$ [9], Table I. This increase in the number of 
binding sites cannot be explained by the assumption that vanadate reduces the affinity of the high affinity calcium binding sites and thereby shifts the calcium binding isotherms to higher calcium concentrations. An increased number of calcium binding sites can only result if vanadate creates more sites of a lower calcium affinity than it abolishes high affinity sites. The precise relation between the number of abolished high and created low affinity

[1] W. Hasselbach, Topics in Curr. Chem. 78, 1-56, Springer-Verlag, Berlin, Heidelberg 1978.

[2] L. De Meis, Transport in Life Science (E. E. Bittar, ed.), Vol. 2, pp. 1-163; John Wiley \& Sons, New York 1981.

[3] P. Medda and W. Hasselbach, Eur. J. Biochem. 137, 7-14 (1983).

[4] U. Pick and S. J. D. Karlish, J. Biol. Chem. 257, 6120-6126 (1982).

[5] W. Hasselbach and M. Makinose, Biochem. Z. 339, 94-111 (1963)

[6] G. Swoboda, J. Fritzsche, and W. Hasselbach, Eur. J. Biochem. 95, 77-88 (1979). sites cannot yet be given. Its evaluation would require the monitoring of the membrane's low affinity calcium binding sites at saturating concentrations in the presence and the absence of vanadate. In the millimolar range of calcium, the total number of low affinity sites amounts to approximately $100 \mathrm{nmol} / \mathrm{mg}$ [11]. Hence, the appearance of a few new sites is very difficult to ascertain.

[7] W. Fiehn and A. Migala, Eur. J. Biochem. 20, $245-248(1971)$

[8] Y. Dupont, Eur. J. Biochem. 109, 231-238 (1980).

[9] W. Hasselbach, P. Medda, A. Migala, and B. Agostini, Z. Naturforsch. 38 c, 1015-1022 (1983).

[10] W. Hasselbach, in: Molecular Bioenergetics and Macromol. Biochemistry (H. H. Weber, ed.), pp. 149171, Springer Verlag, Berlin, Heidelberg 1972.

[11] W. Hasselbach and V. König, Z. Naturforsch. 35c, 1012-1018 (1980) 